\title{
A Rapid Screening Psychometric Test
}

\section{Evaluation of the Kent Emergency Scale}

\author{
FERNANDO J. DE CASTRO, M.D.,* KENNETH L. VAUGHN, M.D.,** \\ RALPH M. GIBSON, PH.D.*
}

W cational or psychologic problems, an appraisal of his inteligence becomes an integral part of the diagnostic survey. The need for an effective screening device for mental age is emphasized by the finding that pediatricians' clinical estimates are often inaccurate.1,2

There are several screening tests which could be used by pediatricians (Ammon, Kent, Peabody, Gooderough, etc), 10 The validity of the Ammon Quick Test as a screening device for mental age has been shown both in the psychologic literature 11,12 and in the pediatric literature. The usefuhness of the Kent Emergency Scale * as a screening device for mental age has been reported in the psychologic literature; $13-20$ however, its usefulness in the hands of pediatricians has not been studied previously.

This report describes an evaluation of the validity of the Kent Emergency Scale as used by pediatricians in an outpatient unit.

\section{Testing Methods}

Six intelligence tests were used in this comparative study. Four of them-Stanford-Binet, Leiter, Weschler, Wescher Intelligence Scale for Children-are fomal psychometric tests

From the Deparmen of Pediatrics, Univenty of Herom

Presented in pat a the Anerican Peditric $3 \mathrm{acte}$ Meeting Nay, 1968.

Supported in part by $\mathcal{U}$. $S$. Children's Bureau grant 616.

Correspondence (F) Und Unersity of Muchigan Medical Center, Department of Pediatric, Ann Arbor, Mich 48104 .

- Instructor of Pediatrics, University of Michigan.

* Associate Professor of Pedatrics, University of Nichigan. which must be administered by clinical psychologists. The other two-the Kent Emergency Scale and the Ammon Quick Test -are screening tests which can be utilized by practicing pediatricians. The applicability of the Armmon Quick Test in pediatrics has been reported by Press et al.

The four above mentioned formal psychometric tests and the Ammon Quick Test were used in this work to measure the validity of the Kent Scale as a tool in the hands of pediatricians.

The Kent Emergency Scale is administered orally by asking sets of questions which are graded according to the patient's age. There are four subsidiary scales. A, B, C, D. Scale A consists of 25 questions and covers mental ages from five to seven years. Scale B consists of 30 questions and covers mental ages from six to eight years. Scale C consists of 27 questions and covers mental ages from six and onehall to 11 years. Scale D consists of ten questions and covers mental ages from eight to $14+$ years. By answering the questions, the patient obtains a raw score which is then converted to mental age by standardized tables provided with the test -1 Representative questians of the Ken Emergency Scale ate repro duced in Table 2 .

The Ammon ouick Test fused here for comparison) asks hie patent to indicare, by pointing, which of the four drawings on three printed cards best illustrates the meaning of

* The Kent Imergency scale can be obtained from The Psychological Corporation, 304 East 45 th Street, New York, N, Y, 10017.

t The Ammon Quick Test can be obtained from the Psychological Test Speciatists, Box 1441, Missoula, Montana 50801 . 


\section{A RAPID SCREENING PSYCHOMETRIC TEST}

a given word. The words are read by the tester from standardized lists graded in order of increasing difficulty. Testing with a given list continues until the patient has had six consecutive failures. The total number of correct responses yields a raw score which is then converted to a mental age by standardized tables provided.s

To investigate the reliability of the Kent Emergency Scale the following experiment was designed. Eighty patients (ages six to 18 years) who required psychologic testing were selected. These patients were split into two groups of 40 each. Patients in group A were tested by either of two pediatricians (F. J. dG. or K. L. V.) with the Kent Emergency Scale, and by one of four clinical psychologists using a Weschler, a Stanford-Binet or a Leiter Test. Patients in group $B$ were tested by one pediatrician (F, J dC.) who used both the Ammon Quick Test and the Kent Emergency Sacle. The realings for mental age obtained by either the Kent Emergency Scale or the Ammon Quick Test were converted into 1.Q. by dividing each of these mental ages by its respective chronologic age and multiplying by 100.

\section{Results}

In group $A$, the mean 1.Q. obtained by the pediatricians was $82 \pm 15.3( \pm$ S.D.); by the psychologists, $83 \pm 15.4$ ( + S.D.). The distri-
TABLE 1. Distribution of $1 . Q$ in Groups $A$ and $B$

\begin{tabular}{|c|c|c|c|c|}
\hline \multirow[b]{2}{*}{ I.Q. } & \multicolumn{2}{|c|}{ Group A } & \multicolumn{2}{|c|}{ Group B } \\
\hline & Kent & $\begin{array}{l}\text { Psychol. } \\
\text { Results }\end{array}$ & Kent & Ammon \\
\hline Below 50 & $\begin{array}{c}1 \\
(2.5 \%)\end{array}$ & $\begin{array}{c}1 \\
(2.5 \%)\end{array}$ & 0 & 0 \\
\hline $50-59$ & $\frac{2}{(500,0)}$ & $\begin{array}{l}2 \\
(5.0 \% 0)\end{array}$ & 0 & 0 \\
\hline $60-69$ & ${ }^{5}(12.5 \%)$ & $\begin{array}{l}4 \\
(4.0 \%)\end{array}$ & $\begin{array}{l}3 \\
(7.5 \%)\end{array}$ & $\begin{array}{l}1 \\
(2.5 \%)\end{array}$ \\
\hline $70-79$ & $\begin{array}{l}9 \\
(22.5 \%\end{array}$ & $\begin{array}{l}7 \\
(17.5 \%)\end{array}$ & $\begin{array}{l}6 \\
(15.0 \%)\end{array}$ & $\begin{array}{l}9 \\
(22.5 \%)\end{array}$ \\
\hline $80-89$ & $\begin{array}{l}10 \\
(25.0 \%)\end{array}$ & $\begin{array}{l}12 \\
(30.0 \%)\end{array}$ & $\begin{array}{l}10 \\
(25.0 \%)\end{array}$ & $\begin{array}{c}7 \\
(17.5 \%)\end{array}$ \\
\hline $90-110$ & $\begin{array}{c}13 \\
(32.5 \%)\end{array}$ & $\begin{array}{l}14 \\
(35.0 \%)\end{array}$ & $\begin{array}{l}20 \\
(\$ 0.0 \%)\end{array}$ & $\begin{array}{l}21 \\
(5.2 \%)\end{array}$ \\
\hline Above 110 & 0 & 0 & $\begin{array}{l}1 \\
(2.5 \%)\end{array}$ & $\frac{2}{(5,0 \%)}$ \\
\hline Totax & 40 & 40 & 40 & 40 \\
\hline
\end{tabular}

Tabue 2, Represenhatio Questions of the Kent Emergensy Scale

Scale A: Which is larger, a cow or a sheep?

Scale B. Tell me a bird that can swim.

Scale C: Wat dowe call a tadpole after it grows up?

Scale D. If a flag floats to the South, from what direction is the wind?
Fla $1 ., \mathrm{Q}$, differences between Kent and psychologisi restits in grotapt

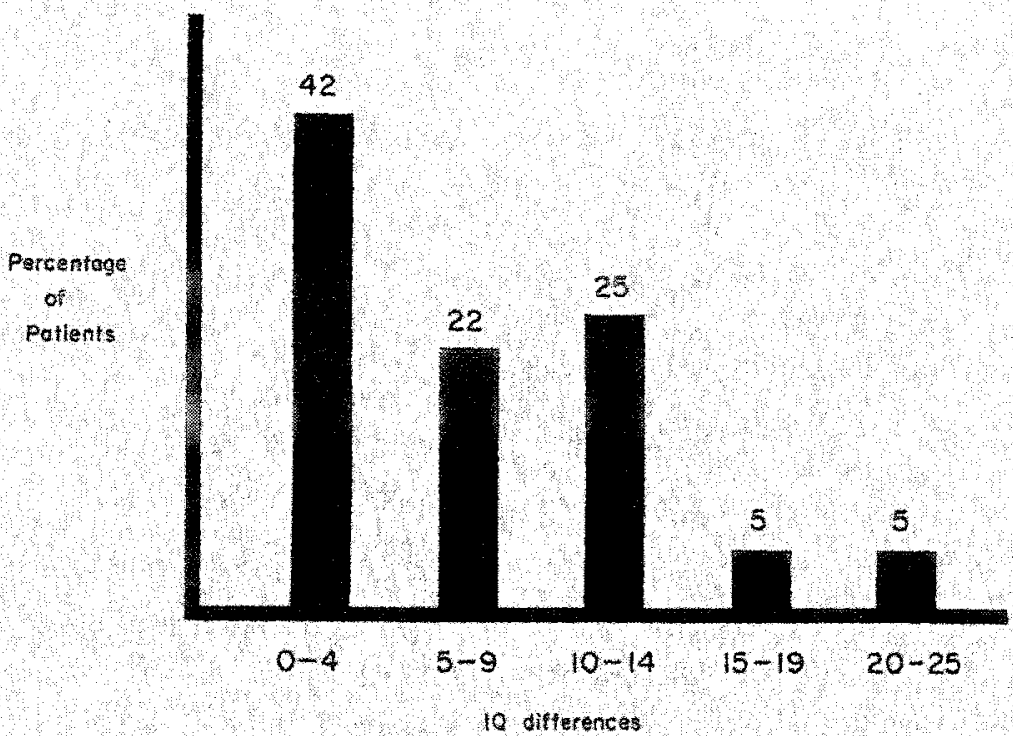




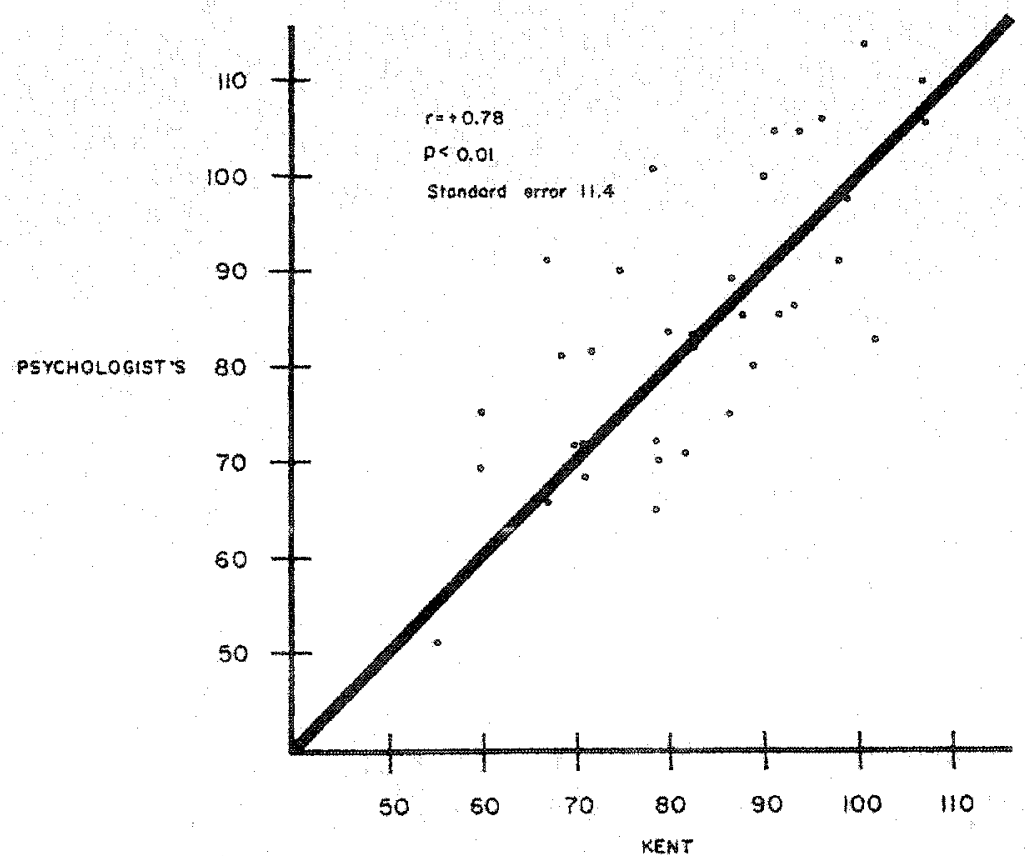

FiG. 2. Relationship between I.Q. scores obtained by Kent test and by psychologist's evalu. ation.

bution of the readings is shown in Table 1 . The differences between pediatricians' results and psychologists results were 0 to $4 \mathrm{l} . \mathrm{Q}$. units in 42 per cent of the patients; 5 to 9 I.Q. units in 22 per cent 10 to 14 I.Q. units in 25 per cent; 15 to 19 1.Q. units in 5 per cent; 20 to 251.2 units in 5 per cent (Fig. 1 ).
The standard error of the estimate was 11.4 1.Q. units and the correlation coefficient was $+0.73(p<0.01)^{\bullet}$ (Fig. 2$)$.

In group $B$, the mean $1 . Q$. obtained by the Kent Emergency Scale was 89 and by the Anmon Quick Test 90. The distribution of the IQ. readings can be seen in Table 1. The

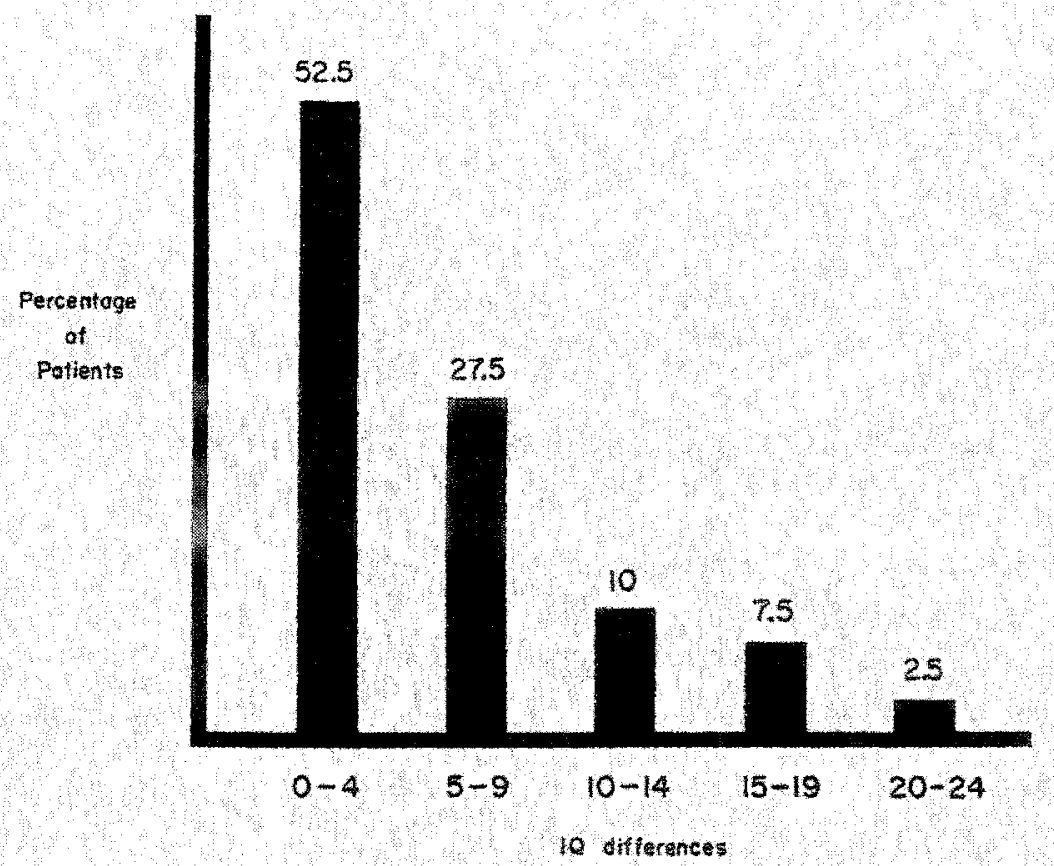

Fid 9 . o. wiferentes be ween Kent and fmmon tests it group $\mathrm{B}$. 


\section{A RAPID SCREENING PSYCHOMETRIC TEST}

Fic. 4. Relationship between I.Q. obtained by Kent and Am. mon tests.

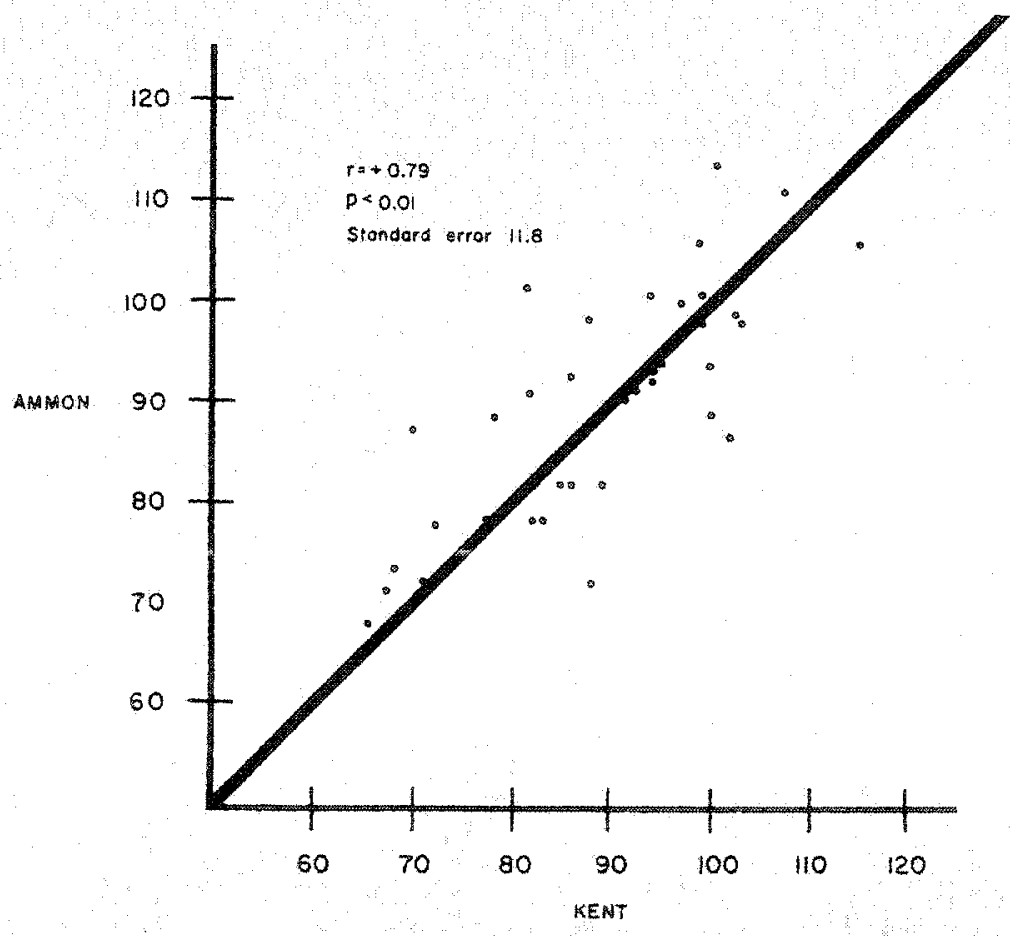

difference between I.Q.' s obtained by each one of these two tests were: 0 to 4 1.Q units in 52.5 per cent of the patients; 5 to 9 I.Q. units in 27.5 per cent; 10 to $14 \mathrm{I}, \mathrm{Q}$. units in 10 per cent; 15 to 19 units in 7.5 per cent; 20 to 24 units in 2.5 per cent (Fig. 3). The standard error of the estimate was 11.8 units and the correlation coefficient $+0.75(p<0.01)^{\circ}$ (Fig. 4).

\section{Discussion}

For appraisal of intelligence the formal psychometric tests (Leiter, Stanford-Binet, Weschler, etc.) require special training in psychology, are time consuming, and require the services of a trained psychologist. The need for a rapid reliable test for mental age which can be peromed by a pediatrician is clearly obvious.

When we compare the Kent Scale with the Ammon Test Rrome the standpoine of ease of administration, we found that the Kent Scale was a few minutes faster to administer than the Ammon Test. Although the Ammon Test has a wider age range than the Rent Scale (one and one-half years to adult versus five to $14+$ years), the Kent Scale offers the advantage of employing simple equipment and of not requiring, as does the Ammon, the use of fairly large cards with pictures.

When we compared I.Q.'s obtained by the Kent Scale with those obtained by Ammon Tests and by formal psychometric tests, the differences were small. Only 10 per cent of the patients showed L.Q. differences of 15 or more 1.Q units, and 90 per cent showed differences of 14 or less (Figs. 1 and 2).

One should be cautious in accepting I.Q. values obtained by screening tests because an error of a few points might be crucial for a specific patient. ${ }^{21}$ But in the normal range of intelligence 14 or less $\mathrm{L} . \mathrm{Q}$. units difference is not at all a high figure. Since our results sug. gest that the Kent Emergency Scale tends to underestimate rather than overestimate 1.Q., it could be assumed that children found func. tioning within the normal range of intelli. gence by the Kent test are likely to be found within whis ratge where tested by fomal poy. chometric tests.

The calculated correlation coefficient of +0.78 when the Kent Scale results (obtained by pediatricians) are compared with results obtained by clinical psychologists, and of +0.79 when Kent Scale results and Ammon Quick Test results are compared, are statis- 


\section{DE CASTRO, VAUGHN AND GIBSON}

tically significant $(p<0.01)$. These correlation coefficients of +0.78 to +0.79 are even more significant if we realize that correlation coefficiencies ranging from +0.69 to +0.93 have been reported in comparing Leiter Scale with Stanford-Binet and correlation coeffcients of +0.77 to +0.83 have been reported when the Leiter Scale is compared with the Weschler Intelligence Scale for Children.22, 23

These results confirm that the Kent Emergency Scale is of significant reliability as a screening test for mental ages when compared with the Ammon Quick Test and with formal psychometric tests performed by clinical psychologists.

\section{Acknowledgment}

We thank Drs. William J. Oliver, James L, Wilson and Ruth $H$. Strang for their enconragement and constructive criticisins.

\section{References}

1. Bakman, R. M.: Office evahuation of intelligence in children. Pediatrics 23: 989, 1959

2. Korsd, B., Colb, K, and Ashe, B.: Pediatrician's appraisal of patient's intelligence Ibid, 27: 990, 1961.

3. Pless, 1. R., Suider, A., Eaton, A. E, and Kearlsley, R. B. A rapid screening test for intelligence in children. Amer, J, Dis, Child. 109, 533, 1965.

4. Tent G, H. Series of Energency Scale. New York, The Psychological Corp, 1946.

5. - Tentative horms of energency battery J Psychol. 15: $137,1943$.

6. _- Emergency battery of one minute test. Ibld, 13: 141, 1942.

7 - The Andores school entrance test $J$. Educ. Psychol 35, 108, 1944 .

8. Ammon, R B. and Ammon, C. H.: Quick test (QT), provisional manual. Psychol. Rep. Monography Supp. 1: 111, 1962.
9. Dixon, W. J and Massey, F. J.: Introduction to Statistical Analysis, New York, McGraw-Hill Book Co., 1957, p. 189.

10. Lessing, E. E.. Note on significance of discrepancies between Goodenough and Binet IQ scores. J. Cons. Psychol. 25: 456, 1961.

11. Carlisle, A. L.. Quick test performance by institutional retardates. Psychol. Rep. 18: $489,1965$.

12. Methwin, M.) Quick performance of mentally retarded individual. Amer. J. Ment. Defic. 68 : 540,1964 .

13. Mullen, F. A.: Comparison of the revised Kent Emergency test with revised Stanford-Binet and Kuhlman-Anderson test. J. Psychol. 15: 151, 1963.

14. Cofer, C. H. and Biegel, M. M.: A study of the Kent and Buck screening test of mental ability in relation to Oxis and standard achievement test scores. J. Cons. Psychol. 12: 187, 1948.

15. Hunt, W. A. and Stevenson, I.: Psychological testing in military dinical psychology; 1 . Intelligence testing. Psychol. Rev, 53: 25, 1946.

16. Hunt, W. A., Wiltson, C. L., Harris, H. I., Solomon, P. and Jackson, M. M.: Psychometric procedures in detection of neuropsychiatrically unfic U. S. Naval Med. Bull. 41: $471,1943$.

17. Lewinski, R. J.: Notes on the original and the revised Kent in the examination of naval recruits. I. Educ Psychol 35 : 554, 1944 .

18. - Performatace of naval tecruits on Kent oral emetgency test and the verbal battery of the Bellewe-Weschler adult intelligence scale Amer. 1. Orthopsychol. $13: 198,1943$.

19. Rudolph, $C$. de M. The Kenc and other tests used on the same subjects. ]. Ment, Sci. $44,452,1948$.

20. Wright, H. F, Mcehee, H. M. and Cummings, S. B.: The relationship between the Kent emergency and the Bellevue verbal scale J. Abnorm. Psychol 44: 223, 1949.

21. Silverstein, A. B.: Validity of short form of intelligence test. J. Cons. Psychol 29. 392, 1965.

22. Little, W, N. Weschlet intelligence scale for dhil dren; review of a decade of research. Psychol Brit 57: 192, 1960.

23. Werner, E, E, In Mental Measurement Yearbook, 6th ed, Kisen, O. K, ed, Gryphon Press, 1965, p. 256

\section{The Law and the Customs}

For years, with medicolegal cases, the courts have decided that physi. cians and hospitals being sued for malpractice may take refuge in the general principle that conformaty with the stambards and customs of practice in the local community is a basic criterion for deciding whether there had been negligence ot other defects in care. The Su. preme Court of the State of Washington, in 1967 , questioned the narrow "locality" limitations in revers. ing a judgavent of a lower court.
The Washington Supreme Court noted that the "locality role" had been developed at a tine when the opportunities and resources for keeping abreast of developments in medical care varied greatly between those in smat rural communities and those in large metropolitan centers.

'The localixy rule' has no pres. entday validity except that it may be considered as one of the elements to determine the degree of skill and care which is to be ex. pected of the average practitioner of the class to which he belongs. ?
The court also stated,

"The standard of care is that estabished in an area coextensive with the medical and professional means avalable in those centers that are readily accessible for ap propriate treamenc of the patient"? It indicated that the standard of care prevailing in Seattle would be applicable also in Aberdeen, miles away, in the case under review, From "Darling Case Reuisted" pre. pared by the $1 M A$ Law Division, JAMA 206:1875, 1968 . 